\title{
The Impact of COVID-19 on Users' Visit to the Shopping Centers in Libya
}

\author{
Hafith Mohammed Sulayman Almansouri ${ }^{1, *}{ }^{*}$, Mehmet Cetin $^{1}(\bullet)$ \\ ${ }^{1}$ Department of Landscape Architecture, Kastamonu University, Kastamonu, Turkey \\ *Corresponding author: hafithm.s.almansouri@gmail.com
}

Received: 30.04.2021 Accepted: 01.06.2021

\begin{abstract}
The impacts of COVID-19 pandemic are expected to be challenging on all countries worldwide, especially from an economic concept. Reformations in the world's economic system and changes in human precautions and behaviors are expected to influence several other aspects directly and indirectly. This paper aims to evaluate the impact of the pandemic on the behaviors and perceptions of shopping malls' users. Through the performed questionnaire on the residents of Dernah, Libya, it was found that they depend on cars as a main mean of transportation. Thus, no major impacts were found on the user's choices in that aspect. However, evaluations of the scale reflect changes of people's attitudes towards their preferences for shopping malls. These results are significant indicators in directing the attention of designers and managers of shopping malls to adopt new strategies and approaches.
\end{abstract}

Keywords: COVID-19; shopping mall; reformation

\section{Introduction}

Tourism provides livelihoods for millions of people and allows billions more to appreciate their own and different cultures, as well as the natural world. For some countries, it can represent over 20 per cent of their GDP and, overall, it is the third largest export sector of the global economy. Tourism is one of the sectors most affected by the COVID-19 pandemic, impacting economies, livelihoods, public services, and opportunities on all continents. While sustaining the livelihoods dependent on the sector must be a priority, rebuilding tourism is also an opportunity for transformation with a focus on leveraging its impact on destinations visited and building more resilient communities and businesses through innovation, digitalization, sustainability, and partnerships (UNSDG, 2020).

Tokazhanov et al. (2020) reviewed literature material to study the impact of the pandemic on elements of sustainability in design of residential units. The authors recommended the reconsideration of architectural and engineering requirements to adjust to health and safety needed measures. Fezi (2020) suggested a "health engaged" architecture that looks into the needs of users in the new era. Effects on design elements are expected to extend to all possible elements including scales and dimensions, ventilation control, and layouts. The author 
suggested that sustainability certification bodies to lead the movement towards the new requirements. Ahsan (2020) proposed several solutions for architecture in post-pandemic, which included reverting to successful techniques from historic civilizations and focusing on sustainability. Based on these studies and the persistent professional viewpoints of the eventual changes in architecture and design during and after the COVID-19 pandemic, it is important to understand the change in user behaviors and preferences.

\section{Literature Review}

\subsection{Pandemic Challenges to Shopping Malls}

For daily essentials-grocery, bakery, pharmacy-consumers increasingly prefer one-stop shop destinations. Our focus-group participants said they find local neighborhood centers or strip malls most convenient for meeting these daily, functional needs, and they expect to shop less in enclosed malls than they did before.

That, along with the growing strength and convenience of e-commerce, means mall owners will have to work even harder to give consumers a reason to travel beyond their neighborhood to get what they need. Single-purpose malls, where consumers go only to shop from a collection of retailers, will struggle to stay relevant.

As the restrictions imposed to protect public health during the pandemic are eased, people will likely be craving more social interaction. If their functional needs are being met close to home, malls themselves will need to build broader, more dynamic experiences that people cannot find elsewhere. Landlords and retailers need to collaborate creatively to drive foot traffic and boost dwell times to increase their revenue productivity.

Consumers told us that to capture their attention and get them to come back, the new destination mall will need to offer not only a great assortment of food options, as mentioned earlier, but also local or made-in-Canada merchants, a variety of parking and curbside pickup options, a centralized place for product returns (including those bought online), and even green spaces with trees and parkland. Progressive malls are building strategies to create mixed-use spaces that bring together residential, office, entertainment, leisure, health and wellness, and other novel experiences. Our interviewees talked about creating community living-room spaces in malls for people to meet and socialize, or building concept destinations like the mall, or health and wellness center, which would include clinics, pharmacies, and spa services.

"If the mall or store can't provide a great experience, there is no reason to go there because you can just buy what you want online," said one mall owner. Lower-performing enclosed community malls in urban or mature markets are (or will soon become) obsolete. Consumers will be drawn to new mixed-use projects with strong leisure and entertainment offerings that help them find the social interaction they crave, especially now (Powell, 2020).

\subsection{Negative Effects of COVID-19 on Global Tourist Activities}

Potential tourists tend to postpone or cancel their plans for a destination that is plagued by a pandemic, especially when its main features are scarce of effective antivirus drugs and vaccines, the rapid spread of the virus and the damage that can cause to health. In cases of pandemics, tourists cancel their travels avoiding suspect places and people. Such kinds of pandemics directly affect industries such as tourism and retail service sector. The economic consequences of this outbreak will be serious, and they will cause damages not only to the tourist destinations with an important concentration of cases but also at a global level. A 
similar case is the outbreak of SARS in 2002. Tourism is currently -March 2020- one of the most affected sectors and the World Tourism Organization has revised its 2020 forecast for international arrivals and receipts, though it emphasizes that such predictions are likely to be further revised. The United Nations specialized agency for tourism expects that international tourist arrivals will be down by $20 \%$ to $30 \%$ in 2020 when compared with 2019 figures. An expected fall of between $20-30 \%$ could translate into a decline in international tourism receipts (exports) of between US\$300-450 billion, almost one-third of the US\$ 1.5 trillion generated in 2019. Considering past market trends, this would mean that between five- and seven-years' worth of growth will be lost to COVID-19 (Folinas \& Metaxas, 2020).

This immense shock could translate into a drop of 850 million to 1.1 billion international tourists and a loss of $\$ 910$ billion to $\$ 1.2$ trillion in export revenues from tourism, putting 100 to 120 million direct tourism jobs at risk. This is particularly critical as around 80 per cent of all tourism businesses are MSMEs. Considerable challenges lie ahead, including the unknown evolution of the pandemic and how consumer confidence will recover. The global economy is projected to contract sharply by 4.9 per cent in 2020, though the outlook is expected to pick up in 2021, according to the International Monetary Fund. Although countries and international organizations have implemented a range of measures to mitigate the socio-economic impacts of COVID-19 and to stimulate the recovery of tourism, the magnitude of the crisis requires extra efforts and continued support (UNSDG, 2020).

\section{Methodology}

The main aim of the study is to study the effect of COVID-19 pandemic on shopping mall users-based changes that occurred to their behaviors, preferences, and considerations. The scope of the study is focused on measurement in Dernah, Libya. Moreover, the questionnaire tool used in the study is designed to collect data under three main sections:

1. Demographics

2. General changes

3. Specific changes in shopping malls that affect user satisfaction. This part measures using 5-point Likert scale four main aspects:

- Habits,

- Accessibility,

- Design, and

- Health and safety.

Using an electronic collection method, twenty-seven questionnaires were collected from the population. Results are analyzed through a comparison and descriptive statistics. Many limitations surround the current research, as the cause of change is an ongoing event (i.e. COVID-19). Therefore, it would be challenging to provide final and definite conclusions. The current studies available in the literature provide an initial vision to user behavior and design in the new era. Nonetheless, it is beneficial to focus on exploratory studies in order to assess the changes, which can empower future decision-making.

\section{Results}

The first section of the questionnaire collected the demographic data of the sample, which are illustrated in Figure 1. The majority of the participants were males (85\%) and the sample was closely distributed between three age groups. Majority of the participants work at the public sector $(54 \%)$, followed by students $(31 \%)$, and employees of the private sector $(15 \%)$. The vast 
majority of the participants are holding a university degree as a minimum, which reflects a well-educated sample.

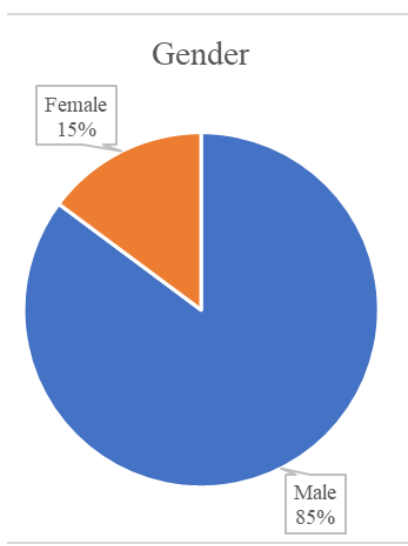

Occupation

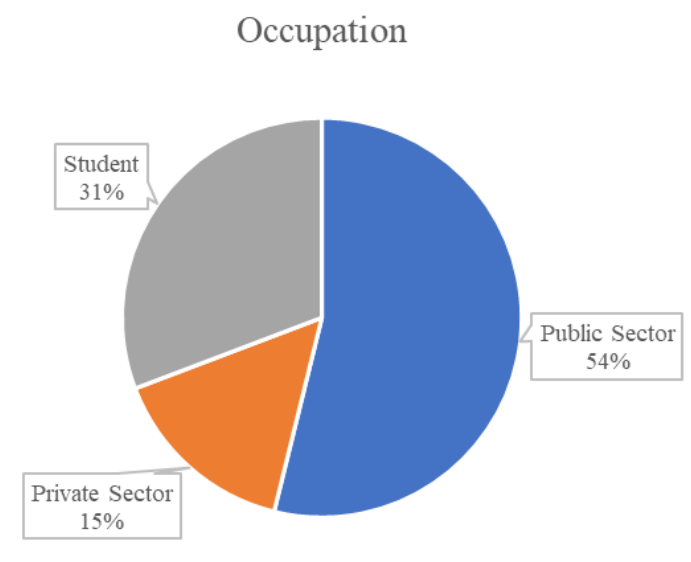

Age

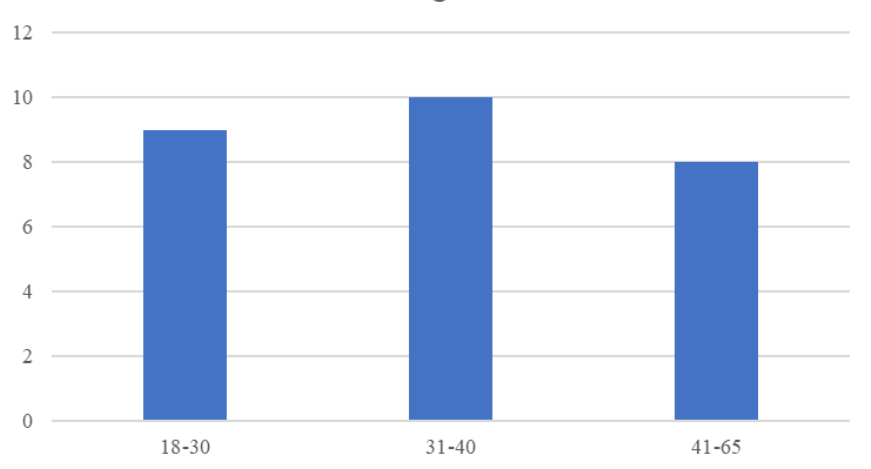

Level of Education

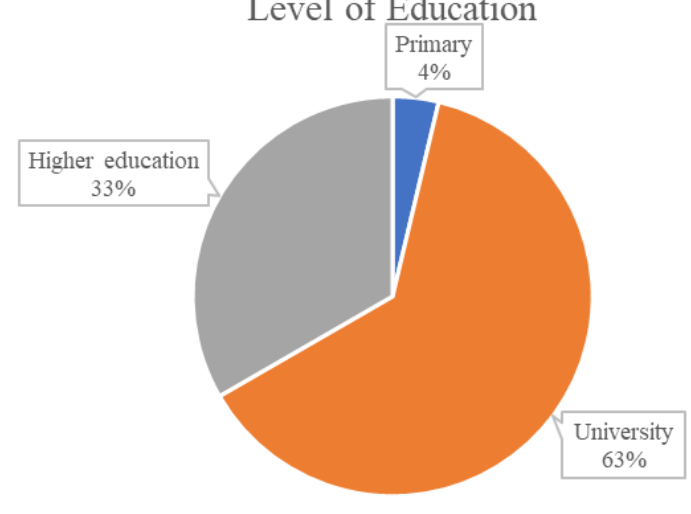

Figure 1. Demographics of participants

In the second section of the study, general differences between before and after the pandemic are measured and compared. Figure 2 compares differences in using means of transportation used to reach shopping malls between the two eras, where no major changes were noticed as users depend on private cares as the main mean of transportation. 


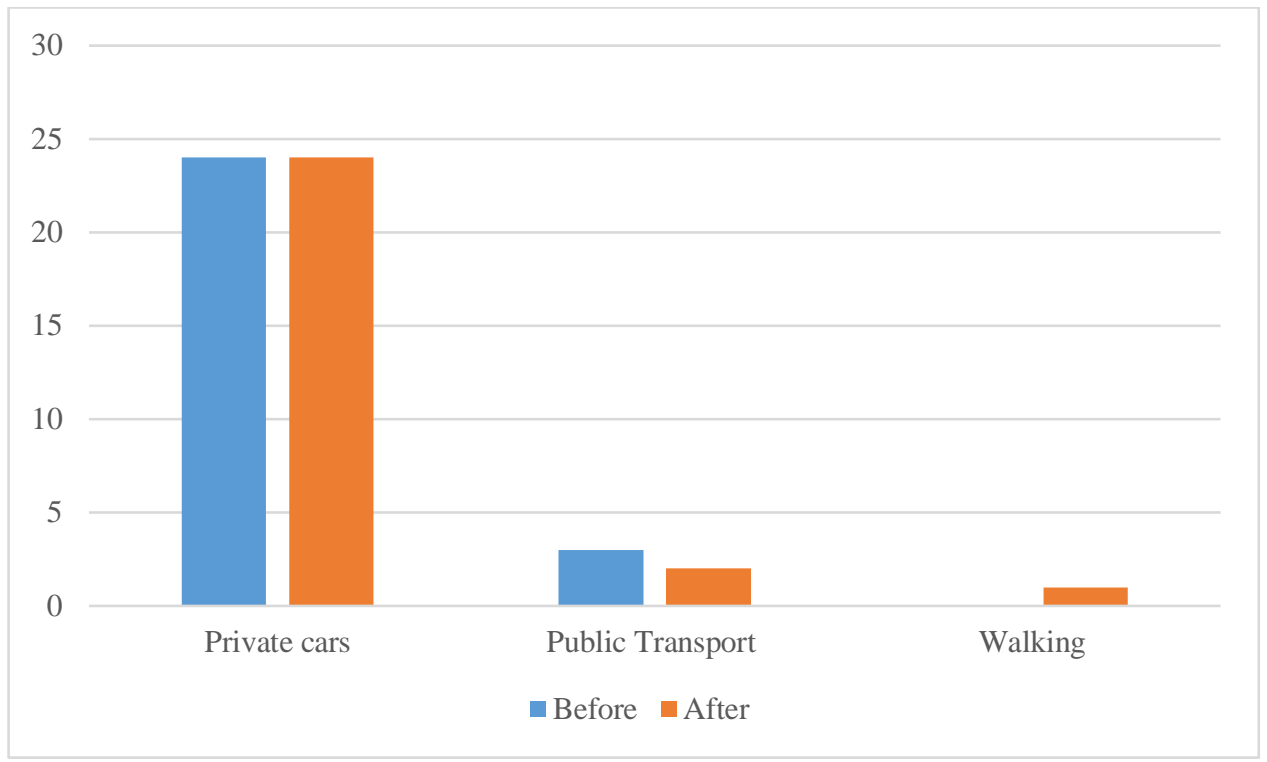

Figure 2. Changes in types of used transport to shopping malls

Figure 3 shows the difference in frequency of visits to shopping malls before and after the pandemic. The results show that the majority of participants were going 1 to 3 times per week, while the number was reduced after the pandemic. A research (Çokyiğit et al. 2019) carried out in three shopping centers of Antalya-Turkey before the pandemic showed that most of the participants $(86 \%)$ preferred shopping malls for the aim of shopping.

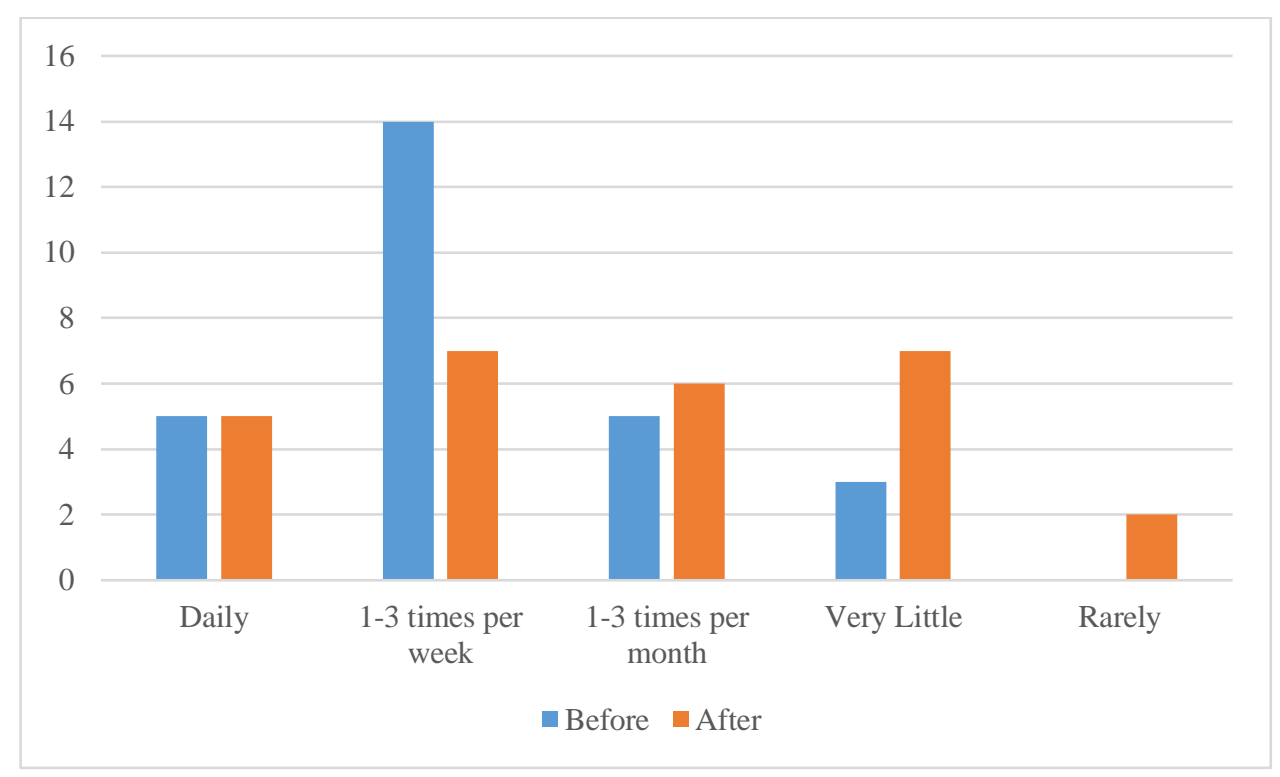

Figure 3. Frequency of visits to shopping malls

Figure 4 shows the preference of the participants to the distance to destination shopping malls. It is evident that more users started preferring close malls after the pandemic, where the majority did not consider distance as a factor before it. 


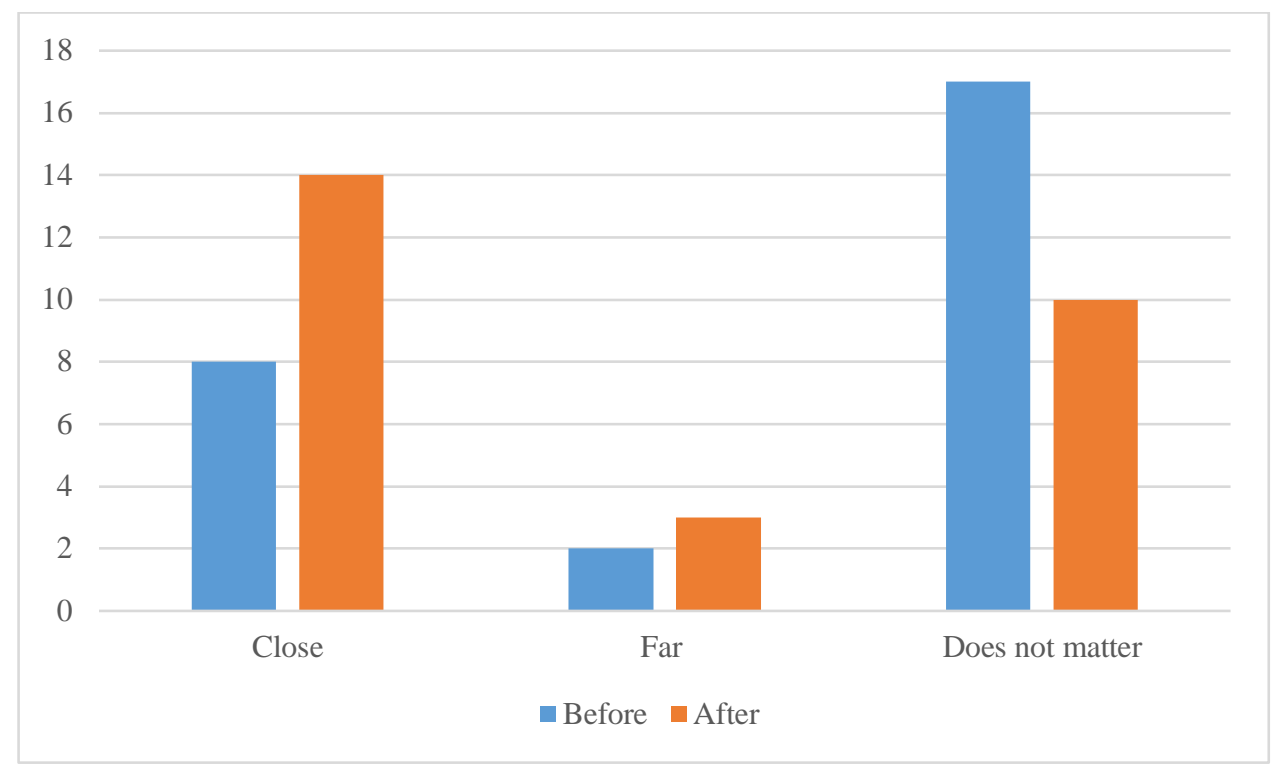

Figure 4. Shopping malls preference according to distance

Figure 5 shows the behaviors of the users in visiting shopping malls, where the majority of the participants started preferring to visit it alone, instead with family or a friend, after the pandemic.

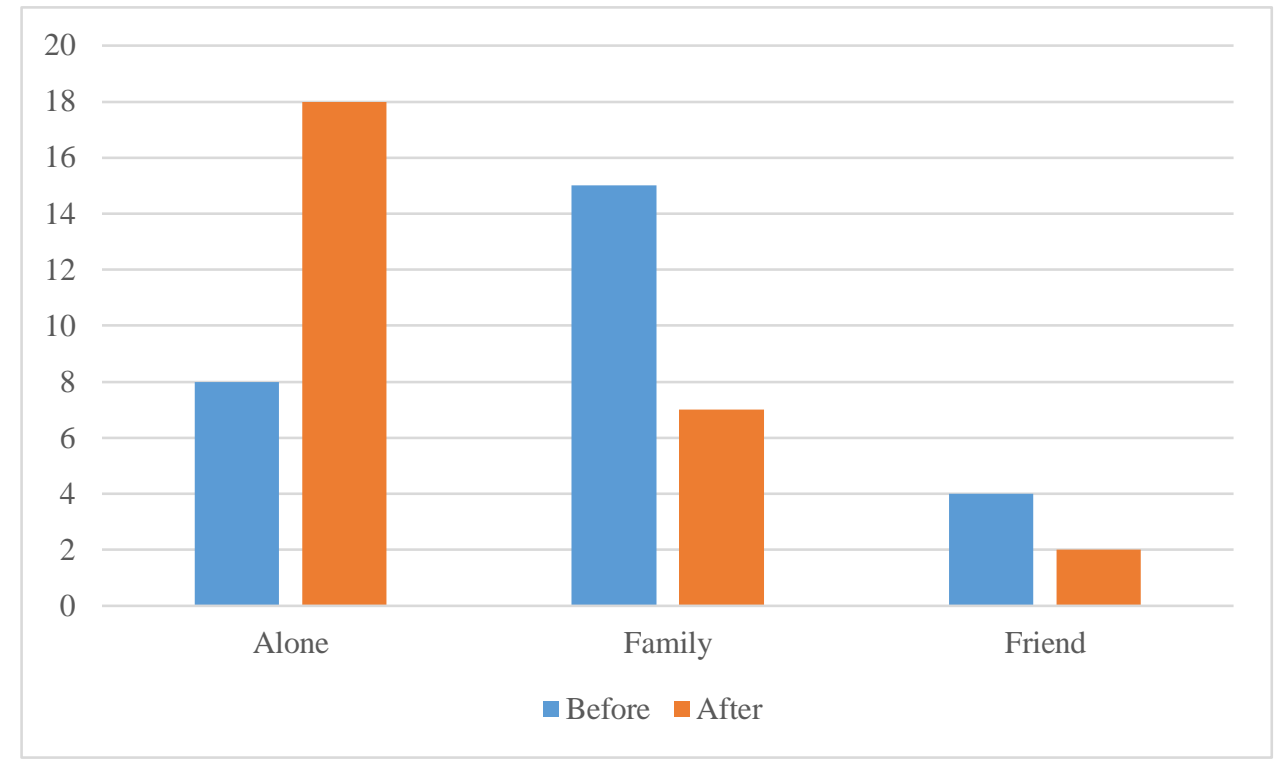

Figure 5. Companion preference in shopping mall visit

In the third section of the study, a scale measuring habits, accessibility, design, and health and safety was measured. Table 1 shows the mean and standard deviation values for each of the twenty-seven items. The indicator that aggregated the highest mean score was for the impact of hygiene and cleanness on reinforcing trust (3.41), followed by the preference of outdoor dining areas (3.37), the preference for shopping malls that are easier to reach (3.33), the preference of spending time in outdoor spaces (3.26), and the priority of caring about cleanness (3.22). Similar to a result in this study, Yücedağ and Çetin (2020) stated that EFL teachers mostly preferred online shopping during pandemic. 
Table 1. Evaluation of shopping malls based on user's preferences after COVID-19 pandemic

\begin{tabular}{|c|c|c|c|c|}
\hline & & Items & Mean & SD \\
\hline \multirow{5}{*}{$\begin{array}{l}\frac{0}{0} \\
\frac{\pi}{\pi} \\
\frac{\pi}{1}\end{array}$} & 1 & Shopping habits had changed & 2.19 & 1.36 \\
\hline & 2 & My preferred working hours had changed & 2.41 & 1.37 \\
\hline & 3 & I prefer online shopping & 2.37 & 1.47 \\
\hline & 4 & I fear from spending long periods in closed spaces & 2.70 & 1.49 \\
\hline & 5 & $\begin{array}{l}\text { While it was an entertaining activity before, shopping had } \\
\text { become for necessities only }\end{array}$ & 2.63 & 1.50 \\
\hline \multirow{8}{*}{ 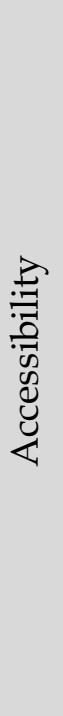 } & 1 & $\begin{array}{l}\text { After the Pandemic, the choice for means of transport had } \\
\text { changed }\end{array}$ & 2.56 & 1.4 \\
\hline & 2 & I go to shopping malls that are easier to reach & 3.33 & 1.69 \\
\hline & 3 & $\begin{array}{l}\text { The location being in the city center affects my decision to } \\
\text { go there }\end{array}$ & 2.37 & 1.50 \\
\hline & 4 & I do not prefer to reach using public transport & 2.89 & 1.65 \\
\hline & 5 & $\begin{array}{l}\text { I use public transports that do not have high density of } \\
\text { users }\end{array}$ & 2.67 & 1.57 \\
\hline & 6 & $\begin{array}{l}\text { It is important for me to have sufficient availability of car } \\
\text { parking }\end{array}$ & 3.00 & 1.57 \\
\hline & 7 & I use stairs in shopping malls & 2.81 & 1.62 \\
\hline & 8 & $\begin{array}{l}\text { Warning and awareness signs affect my preference for a } \\
\text { shopping mall }\end{array}$ & 2.52 & 1.50 \\
\hline \multirow{8}{*}{ 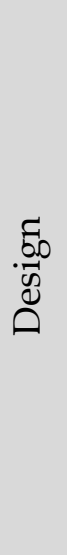 } & 1 & $\begin{array}{l}\text { Architectural design and construction do not affect my } \\
\text { preference }\end{array}$ & 1.78 & 1.09 \\
\hline & 2 & I prefer indoor open spaces & 3.00 & 1.64 \\
\hline & 3 & I try to spend less time in closed indoor spaces & 2.70 & 1.46 \\
\hline & 4 & I prefer spending time in outdoor spaces & 3.26 & 1.68 \\
\hline & 5 & I prefer areas with natural sightseeing & 3.04 & 1.74 \\
\hline & 6 & I prefer outdoor dining facilities & 3.37 & 1.67 \\
\hline & 7 & $\begin{array}{l}\text { socio-cultural facilities, e.g. cinema, playgrounds, etc., are } \\
\text { not the reason behind my choices }\end{array}$ & 2.33 & 1.27 \\
\hline & 8 & The use of touchless equipment affects my choices & 2.33 & 1.27 \\
\hline \multirow{6}{*}{ 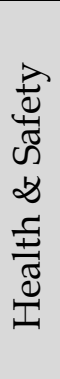 } & 1 & The first thing I care about is the feel that it is clean & 3.22 & 1.85 \\
\hline & 2 & The keep of cleanness and hygiene reinforces trust & 3.41 & 1.72 \\
\hline & 3 & The presence of control points increases my trust & 2.96 & 1.72 \\
\hline & 4 & I do not find children's playgrounds safe anymore & 3.11 & 1.72 \\
\hline & 5 & I do not find dining spaces healthy anymore & 2.70 & 1.44 \\
\hline & 6 & $\begin{array}{l}\text { I think that shopping centers will remain unsafe for a long } \\
\text { time }\end{array}$ & 2.52 & 1.37 \\
\hline
\end{tabular}




\section{Conclusions}

The magnitude of event makes it imperative that COVID-19 pandemic affects and continue affecting human attitudes, habits, preferences, and lifestyles. Therefore, it is highly expected that preferences for shopping malls are also changed after the pandemic. The findings of the current study provide a general comparison between user habit for shopping malls before and after the pandemic, as well as an evaluation of the most important aspects that are considered by users while visiting a shopping mall. Comparisons show that while no effect on preferred means of transportation was found in the Libyan sample, differences were found in users' frequency of visits, preference of distance to shopping malls, and companion preferences. It is indicated that users after COVID-19 pandemic prefer less frequently visiting malls, with preferences for close malls and individual visits. Evaluation of different aspects of shopping mall experiences after the pandemic, it is indicated that hygiene and availability of outdoor spaces are the most important factors influencing user decisions.

\section{Acknowledgments}

As the corresponding author I am studying my Ph.D. at Kastamonu University. This study conducted in Dernah, Libya. Thank you for supporting to the residence of Dernah, Libya. In addition, thank you for this study was conducted by Ph.D. courses of "Tourism Planning and Ecotourism". Thank you for supporting for the course of teachers.

\section{Author Statement}

The authors confirm contribution to the paper as follows: study conception and design: Hafith; data collection: Hafith; analysis and interpretation of results: Hafith and Mehmet; draft manuscript preparation: Hafith. All authors reviewed the results and approved the final version of the manuscript.

\section{Conflict of Interest}

The authors declare no conflict of interest.

\section{References}

Ahsan, M. (2020). Strategic decisions on urban built environment to pandemics in Turkey: Lessons from COVID-19. Journal of Urban Management, 9(3), 281-285.

Fezi, B. A. (2020). Health engaged architecture in the context of COVID-19. Journal of Green Building, 15(2), 185-212.

Folinas, S., \& Metaxas, T. (2020). Tourism: The Great Patient of Coronavirus COVID-2019. Munich Personal RePEc Archive.

Powell, C. (2020). Malls must focus less on shopping and more on experience: Deloitte. Retrieved from The Message: https://the-message.ca/2020/07/13/malls-must-focus-less-onshopping-and-more-on-experience-deloitte/

Tokazhanov, G., Tleuken, A., Guney, M., Turkyilmaz, A., \& Karaca, F. (2020). How is COVID19 Experience Transforming Sustainability Requirements of Residential Buildings? A Review. Sustainability, 12(8732). 
UNSDG. (2020). Policy Brief: COVID-19 and Transforming Tourism. Retrieved from United Nations Sustainable Development Group: https://unsdg.un.org/resources/policybrief- COVID -19-and-transforming-tourism

Çokyiğit, H., Kaya, L.G., Yücedağ, C., Aşıkkutlu, H.S. (2019). AVM'lerde Sergileme Elemanlarının Tüketici Davranışına Etkisi: Antalya Örneği, (Editor: Kaya, L.G. Mimarlık Planlama ve Tasarım Alanında Araştırma ve Değerlendirmeler). Gece Publishing, Basım sayıs1:1, ISBN:978-605-7852-93-9.

Yücedă̆, C., Çetin, M. (2020). Identifying Leisure Perceptions and Activities of EFL Teachers in Home Isolation during the Covid-19 Pandemic. Kastamonu Üniversitesi Mühendislik ve Fen Bilimleri Dergisi, 6(2): 62-72. 